\title{
Homeopathic Approach in the Case of Secondary Infertility and Anosmia
}

\begin{abstract}
Hayriye ALP
Necmettin Erbakan University, GETAT CENTER, Konya, Turkey.

Corresponding Author: Hayriye Alp, Necmettin Erbakan University, GETAT CENTER, Konya, Turkey.

Received date: April 22, 2021; Accepted date: April 29, 2021; Published date: May 04,2021

Citation: Hayriye Alp (2021) Homeopathic Approach in the Case of Secondary Infertility and Anosmia. J of Obstetrics Gynecology and Reproductive Sciences 5(4) DOI:10.31579/2578-8965/073

Copyright: (c) 2021, Hayriye Alp, This is an open access article distributed under the Creative Commons Attribution License, which permits unrestricted use, distribution, and reproduction in any medium, provided the original work is properly cited.

Abstract:

A 38-year-old female patient diagnosed as secondary infertility, anosmia, myoma uteri, Hashimoto thyroiditis with the history of many unsuccessful IVF attempts regained her ability of smell, her thyroid antibody levels normalised, her basal hormones, AMH levels, ovarian follicular development and ovulation improved after 6 months of treatment with homeopathy and nutritional supports. In this case report, it is observed that many gynecological problems accompanied with infertility, anosmia and autoimmune problems like Hashimoto's thyroiditis can be improved with a holistic approach to individual supportive therapies and homeopathy. It is hoped that this case report can be a reference for future studies in this field.

Keywords: homeopathy, anosmia, infertility, hashimoto thyroiditis, GAPS, nutrition, alternative medicine, complementary medicine.
\end{abstract}

\section{Introduction}

The understanding of health and healing in homeopathy is based on the energy force in the body. The term Hahnnemann uses to describe this is life force, life principle.

"In healthy people, the life force... that animates the material organism (body)... prevails without any restrictions and holds all parts of the organism in an admirable, harmonious, vivid manner, both in terms of emotions and functions.... it cannot protect itself. He owes all his feelings and life functions only to this intangible age force. It is the life force that gives life to the material organism in both illness and health. " (one)

Homeopathy does not cure the symptoms of the disease, it strengthens the life energy of the body and ensures that the deteriorated balance is restored. Homeopathy, which handles and treats the individual, which is derived from a single cell, as a physical, emotional and mental whole without dividing it into areas, is the most used complementary medicine treatment method after phytotherapy [1].

Infertility; It is defined as not having pregnancy despite having regular sexual intercourse. Secondary infertility is the inability of couples who have had children naturally before, not being able to conceive spontaneously again. The incidence of infertility, seen in an average of 15-20 out of every 100 couples, increases with age. Infertility, which is a health problem related to the reproductive system, can be caused by either a female or a male or a combination of many factors [2]. It is estimated that infertility affects $8-12 \%$ of couples of reproductive age worldwide. Secondary infertility is usually caused by systemic infections and is the most common female infertility in the world [3].
Successful results can be obtained from homeopathic treatments in cases where conventional medical methods are inadequate or unsuccessful in the treatment of infertility, or in couples who want to avoid the side effects of operative and hormonal treatments $[4,5,6]$.

Anosmia; It is defined as the lack of sense of smell. Kalmann syndrome comes to mind in case of anosmia accompanying infertility. Kalmann syndrome is a genetic disease that can present with heterogeneous clinical pictures in which hypogonadotropic hypogonodism (reduced or absent functions of the ovaries and testicles) can be seen together with anosmia. It is known that it has X-transmitted, autosomal dominant or autosomal recessive forms [7].

Hyposmia or anosmia may also develop due to exposure to drugs and chemicals [8]. Hundreds of drugs or chemicals can induce varying chemosensations as well as unpleasant tastes and odors [9].

Hashimoto thyroiditis; Thyroid gland disease, also known as chronic lymphocytic thyroiditis, is a serious autoimmune disease first described by Japanese scientist Akira Hashimoto in 1912. In Hashimoto's disease, the immune system produces antithyroglobulin and antiTPO antibodies to the thyroid gland. These antibodies damage the thyroid cells, causing a decrease in thyroid hormone, in other words, hypothyroidism. Hashimoto thyroiditis is one of the most common causes of hypothyroidism and may accompany infertility [10].

Homeopathy, in Hashimoto's thyroiditis, an autoimmune disease; It is a successful treatment method in the treatment of many thyroid diseases, 
especially hypothyroidism and hyperthyroidism. There are many scientific studies on this subject [11].

\section{Case Report and Treatment Plan:}

38-year-old female patient E.A., whom we evaluated with diagnoses of anosmia, secondary infertility, Hashimoto thyroiditis; A spontaneous pregnancy and normal birth in 2000; Pregnancy loss with 15 weeks premature rupture of membranes and bleeding in 2004; Myomectomy operation in 2008; In 2016, there was a history of 20 times IVF (IVF) trials, including laparoscopy and total, frozen embryo transfers during this period. She applied to our clinic in July 2018 for child request and in vitro fertilization treatment.

The following findings were found in the admission examination and anamnesis:

Black-brown spots and moles all over the body, common on the face and neck

Ingrown nail and nail deformity in both big toes

Acne in the lower jaw

Dry skin, thin and weak hair, wandering joint and muscle aches

Irregular, intense and painful menstrual bleeding

Operation history due to uterine fibroids

PMS (premenstrual syndrome)

-Weakness, fatigue, inability to enjoy life, depressive symptoms

Common varicose veins in the legs

- Not being able to smell since childhood

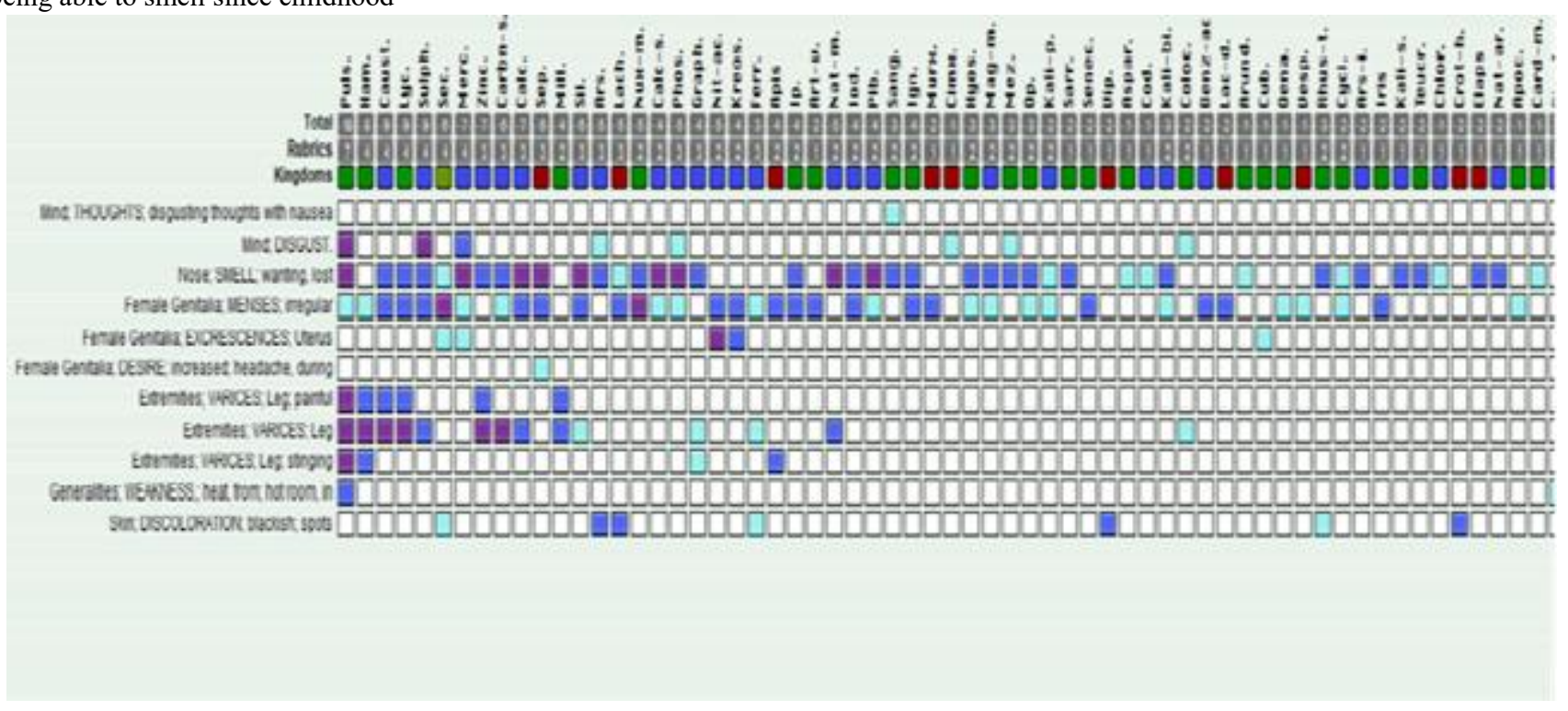

Nutritional advice, lifestyle and stress control counseling were given in this case; Vitamin and mineral deficiencies were detected and treated. In the nutrition of the patient, with the GAPS (Gut And Psychology Syndrome, Intestinal and Psychology Syndrome) diet, it was aimed to improve the permeable intestinal wall due to chronic inflammation, to eliminate the toxic effects on the tissues and organs, thereby psychological and physiological recovery. It is known that comorbid conditions due to disorders in blood glucose and lipid metabolism can be observed in autoimmune thyroid diseases accompanying polycystic ovary
- Not being able to touch beads and round objects, feeling dirty where these objects are located and needing to clean

- Dry mouth, thirst, drinking little water, feeling uncomfortable in hot environments

- Fear of heights and dogs; fear of losing your daughter; feeling guilty and ugly for not being able to conceive

- homeland longing

- History of father and brother pressure and violence in childhood and youth

- Family history of cancer (leukemia in mother, lung cancer in uncle)

Rubrics and repertorization scheme:

- Disgust and disgust with beads and round objects.

Lack of sense of smell

Irregular menstrual cycles

Mass in the uterus

Headaches during mens period

Varicose veins in the lower extremities

- Heat deterioration

Black spots on the skin, moles

These rubrics were repertorized using the MacRepertory (Synergy Homeopathic) computer program. syndrome [18]. Because of the patient's autoimmune problems, the GAPS nutrition protocol was used as part of empirical treatment [12], [16], [17]. The patient's low vitamin B12 values, nutritional regulation and appropriate nutritional supplements $>500 \mathrm{pg} / \mathrm{ml}$; Vitamin D3 values were also increased to $>50 \mathrm{ng} / \mathrm{ml}$.

Homeopathy treatment was initiated by obtaining the informed consent form of the patient whose nutrition was given. Homeopathy treatment was planned according to the result of repertorization performed using the 
"MacRepertory, Synergy Homeopathy" program according to the patient's detailed anamnesis. For thyroid antibodies and thyroid dysfunction, which are high in the homeopathic treatment approach, Thyroidinum C200 (manufactured by Hagalil Pharmacy, serial number R1463723M, containing thyroid node dated 10/07/2018, C200 potency) 2 globule dry doses were given once a week for four weeks. Carbo animalis C200 and 1M (Hagalil Pharmacy production, serial number R426854S (C200), production date 11/12/2017, serial number R4814225M (1M) dated 9/4/2018 containing Carbo animalis, C200 and $1 \mathrm{M}$ potencies) aqueous dose It was given one month apart. With this treatment, the patient's joint and muscle pains improved. A short-term increase in TSH (TSH: 10.35) was observed in the first month of treatment. During this period, homeopathy treatment was continued and followed without the use of thyroid medication, and it was observed that it decreased to normal levels at the end of the second month.

The structural remedy Pulsatilla C200 (Hagalil Pharmacy production, R6710123T (C200) serial number, 24/06/2018 production date) after two months of treatment applied for thyroid disease and determined according to the repertorization to the patient, and Pulsatilla 1M (Hagalil Pharmacy production, R5729080F) one month later The homeopathy treatment was continued with the aqueous dose (serial number $1 \mathrm{M}$, production date 14/04/2018). In this process, in the follicular phase of the menstrual cycle (first 14 days), Folliculinum C30 (Hagalil Pharmacy production, $\mathrm{R} 1463301 \mathrm{H}$ serial number, $27 / 11 / 2018$ production date) was added to the treatment and follicle monitoring was performed with USG and infertility treatment was planned.

At the end of a treatment period of approximately 6 months (July 2018December 2018), the patient started to smell; the menstrual cycle is in order; With significant improvement in premenstrual symptoms, common muscle and joint pain, the patient's quality of life increased. The patient's high thyroid antibodies fell; high TSH and FSH levels returned to normal; Ovarian follicle development and ovulation were observed in ultrasonographic follow-up. There were no more fatigue and depressive complaints. He stated that his sense of smell has returned to normal. The patient, who had full recovery physically and mentally, postponed the IVF treatment, thinking that he could conceive normally. Their follow-up in our clinic continues.

Basal hormone and ultrasonography results before and after treatment are summarized in the tables. (Table 1,2)

\begin{tabular}{|l|l|l|l|l|l|}
\hline Basal Hormones & FSH(Mu/l) & E2(pg/ml) & AMH & TSH(Mu/l) & Anti TPO \\
\hline $\begin{array}{l}\text { Pretreatment } \\
(18 / 07 / 2018)\end{array}$ & 9.7 & 73.95 & 0.2 & 2.39 & $>1300$ \\
\hline $\begin{array}{l}\text { After treatment } \\
(07 / 09 / 2018)\end{array}$ & 8.1 & 55.6 & 0.35 & 1.27 & 15 \\
\hline
\end{tabular}

Table 1: Basal hormone and antibody values before and after treatment

\begin{tabular}{|ll|l|l|l|l|}
\hline USG Findings & & Right ovary & leftt ovary & endometrium \\
\hline $\begin{array}{l}\text { Before } \\
(26 / 07 / 2018)\end{array}$ & treatment: & $\begin{array}{l}33 \mathrm{~mm} \text { cyst, 1-2 9-11 } \mathrm{mm} \\
\text { antral follicles were } \\
\text { observed }\end{array}$ & $\begin{array}{l}2-3 \quad 10-11 \mathrm{~mm} \text { antral } \\
\text { follicles but no active } \\
\text { follicle }\end{array}$ & $\begin{array}{l}\text { Irregular and thin } \\
(5-6 \mathrm{~mm})\end{array}$ \\
\hline $\begin{array}{l}\text { After } \\
31 / 12 / 2018)\end{array}$ & treatment: & $\begin{array}{l}117 \mathrm{~mm} \text { and } 119 \mathrm{~mm} \text { active } \\
\text { follicle was observed }\end{array}$ & $\begin{array}{l}118 \mathrm{~mm} \text { active follicle was } \\
\text { observed }\end{array}$ & Regular $(9-10 \mathrm{~mm})$ \\
\hline
\end{tabular}

Table 2: Transvaginal ultrasonography findings before and after treatment

\section{Discussion}

In autoimmune diseases such as infertility and Hashimoto thyroiditis, TSH level, thyroid antibody levels, ovarian reserves and ovulation can be improved with a holistic approach and a combination of homeopathic treatment. It has been shown with the support of pre- and post-treatment laboratory data.

Pulsatilla Nigricans (Manisa Tulip), the structural remedy of the patient, is a herbal remedy. It is a typical female archetype and the patient starts to smell in a short time with the addition of a remedy that every woman may need once in her life; The recovery of the problems related to menstruation and the return of the ovulatory cycles is a very striking improvement. It has been observed in many cases that pulsatile works wonders in women who cannot get pregnant easily, varicose veins, sinusitis, rhinitis, otitis, cystitis, vaginitis problems, birth and postpartum breastfeeding problems. The use of Pulsatilla to counteract the side effects of Tamoxifen treatment is probably a future reference to help explain the affinity of this homeopathic drug to hormone receptors [13].

The data obtained on animals related to homeopathic studies responds to the criticisms of the "placebo effect" most criticized. Thus; Infertility treatment in bulls has been described in the homeopathic literature. Several treatments have been suggested, such as changing the protein content of the diet, giving extra minerals. It has been reported that a Nelore breed bull thought to be infertile for 3 years was treated with homeopathic Pulsatilla nigricans $200 \mathrm{CH}$. Decreased total sperm defects, increased sperm motility and a very impressive increase in the number of sperm produced have been observed [14].

Chronic sinusitis and allergic rhinitis conditions can also cause anosmia. Pulsatilla, which we used as the structural remedy of our patient, is a remedy with shown therapeutic efficacy in such cases, and his anosmia may also have improved as a result of the recovery of the undiagnosed sinusitis or allergic rhinitis condition in our patient [15].

\section{Conclusion}

Our results obtained with homeopathy, nutrition and supportive therapies are of a nature that can be a reference to further studies within the scope of integrative therapies, showing that the deteriorated life energy and immune system balances in autoimmune and chronic diseases can be corrected and the problems that we cannot overcome with classical treatment methods.

You can find our video of our treatment at https://youtu.be/Gg2_u0vW4EY.

\section{Conflict of Interest:}


The homeopathic medicines used in the treatment are indicated by their open brand name because the source and production information can be provided. Turkey, which is already licensed homeopathic medicine is used homeopathic medicines registered abroad is not available, we do not have a commercial relationship with the company.

\section{References}

1. Schepper L. Bölüm, Sağlık ve İyileşmede Yaşam Gücü.(2019) Hahnemann' Yeniden Okumak bask1. İstanbul: Mavi Yelken Yayıncılık. p. 11

2. Fıçıcıoğlu C.,3.Bölüm,(2019) İnfertilite Nedenleri ve İnfertil Çiftin Değerlendirilmesi. Üreme Endokrinolojisi, İnfertilite Ve Yardımcı Üreme Teknikleri. İstanbul: Nobel Tıp Kitapevleri; Eylül . p. 43

3. Vander B., Mélodie; WYNS, Christine.(2018) Fertility and infertility: Definition and epidemiology. Clinical biochemistry, 62: 2-10.

4. Sreevidhya JS. (2018). Treating female infertility: A homeopathic approach.

5. Masiello DJ, Evrony DOA, Loike JD (2017) Homeopathic Treatment of Infertility: A Medical and Bioethical Perspective. Int J Complement Alt Med 5(5): 00167. DOI: 10.15406/ijcam.2017.05.00167

6. PAL, Partha Pratim; NATH, Madhumita.(2019) Infertility cured by dynamic potencies. International Journal of Research and Analytical Reviews .6.1

7. Waltham MA. (2014). New Elsevier Reference Module in Biomedical Sciences Now Available. Elsevier.

8. Jafek BW1, Linschoten MR, Murrow BW. (2004)Anosmia After Intranasal Zinc Gluconate Use . Am J Rhinol. 18(3):137-41.

9. SCHIFFMAN, Susan S.(2018) Influence of medications on taste and smell. World journal of otorhinolaryngology-head and neck surgery, 4.1: 84-91.

10. Fritz M. \& Spetoff L.(2011) Reproduction and the Thyroid.: Seigafuse S., Clinical Gynecologic Endocrınology and Infertility. 8.th ed. Philadelphia, USA: Lippincott W.\&W. p. 885-892.

11. Mr. Suraj Narayan Mali et al.(2017) Hypothyroidism and alternative treatment an overview Ijsrm.Human, ; Vol. 6 (1): 3852.

12. Campbel-MacBride N.GAPS Bağırsak ve Psikoloji Sendromu (Otism, Şizofreni, Depresyon, D.E.B., D.E.H.B.(2017), Disleksi, Dispraksi) İçin Doğal Tedavi Yöntemi.19.baskı. İstanbul; Adalin Yayınc1lik.p.301-316

13. BAGOT, Jean-Lionel(2018); DELÈGUE, Clara. My best case: homeopathic management of adverse effects of tamoxifen. Wiener Medizinische Wochenschrift, 2018, 1-6.

14. LOBREIRO, J. (2017)Homeopathic treatment for infertility in a prize Nelore bull. Homeopathy, 2007, 96.01: 49-51.

15. NAYAK, Chaturbhuja, et al.(2012) Homeopathy in chronic sinusitis: a prospective multi-centric observational study. Homeopathy, 101.02: 84-91.

16. VIRILI, Camilla, et al.(2018) Gut microbiota and Hashimoto's thyroiditis. Reviews in Endocrine and Metabolic Disorders, 19.4: 293-300. 